\title{
Predictors of Self-Directed Learning Readiness of Nursing Students
}

\author{
Maria Grandinetti \\ Wilkes University, Wilkes-Barre, USA
}

\begin{abstract}
Attrition is a major concern in schools of nursing, and research shows that it is most prevalent in baccalaureate nursing students as they first encounter their initial nursing and core science courses. Nurse educators anticipate that beginning nursing students have the potential to be self-directed learners; and have the initiative to independently identify and implement resources and strategies for learning. A concept analysis of self-directed learning (SDL) identified motivation to learn, learner independence, and intellectual curiosity as the primary antecedents of this phenomenon. The purpose of this descriptive correlational study was to explore the relationships among motivation to learn, learner independence, intellectual curiosity, and self-directed learning readiness (SDLR) of baccalaureate nursing students. Imogene King's Theory of Goal Attainment (TGA) and Malcolm Knowles' Adult Learning Theory (ALT) served as a theoretical basis for this study. The target population and setting was sophomore baccalaureate nursing students at four randomly selected accredited schools of nursing across the United States (U.S.) holding chapter membership in Sigma Theta Tau International (STTI). Data analyses included descriptive and inferential statistics appropriate to answer the study's research questions and to test the hypothesis. Study findings revealed statistically significant evidence that these nursing students scored moderately high on measures of motivation to learn, learner independence, and intellectual curiosity for nursing education. Furthermore, the linear combination of the predictor variables of learner independence and motivation to learn predicted SDLR in baccalaureate nursing students better than anyone variable alone.
\end{abstract}

Keywords: higher education, innovative teaching, learner independence, motivation to learn, learning support

\section{Introduction}

Knowles (1975) defined self-directed learning (SDL) as one in which "Individuals take the initiative, with or without the help of others, in diagnosing their learning needs, formulating learning goals, identifying human and material resources for learning, choosing and implementing learning strategies, and evaluating learning outcomes" (p. 18). Similarly, Ainoda, Onishi, and Yasuda (2005) reported that SDL is often associated with being a lifelong and independent learner. SDL is "an approach where learners are motivated to assume personal responsibility and collaborative control of the cognitive and contextual processes in constructing and confirming and worthwhile learning outcomes" (Garrison, 1997, p. 18). Garrison hypothesized that SDL needs to be viewed from a "collaborative constructivist" perspective, where the learner takes responsibility for constructing meaning while including the participation of others in confirming worthwhile knowledge. Garrison strongly suggested that learners should be provided with choices of how they wish to learn; including

Maria Grandinetti, Ph.D., RN, BSBA, assistant professor, School of Nursing, Wilkes University. 
providing input on the material resources that should be available to energize meaningful and continuous learning. He theorized that the collaborating dimensions of motivation, self-monitoring, and self-management are what lead to SDL. A student's readiness for SDL is what is significant and warrants investigation. A concept analysis of self-directed learning readiness (SDLR) was conducted in advance of this study by this researcher. Based on an extensive literature review in the disciplines of nursing, education, and psychology, motivation to learn, learner independence, and intellectual curiosity were identified as being primary antecedents of this phenomenon.

\section{Problem Statement}

The statistics are ominous: One million new or replacement nurses are needed in the United States (U.S.) by the year 2016; an increase of $30 \%$ in the number of nurse graduates annually over the current numbers is needed to meet the nation's health care needs; and $55 \%$ of current nurses are planning to retire between the years of 2011 and 2020 (American Association of Colleges of Nursing (AACN), 2012). As a result, there is a continuous rise in the need for qualified registered nurses to enter the profession. Due to the difficult and rigorous nature of nursing education, student retention and attrition are currently major problems for nurse educators (Robinson \& Niemer, 2010). This researcher was primarily concerned with the high probability that there are students who are both accepted and enrolled in baccalaureate nursing programs that lack SDLR.

The concept of SDL has been investigated nationally and internationally in the disciplines of psychology, education, nursing and allied health, and business. As compared to the numerous published studies about SDL in the area of adult education, there were few published studies that look specifically at SDL in sophomore baccalaureate nursing students who are enrolled in early nursing and science courses for this major. There were even fewer studies investigating the consequences of students who lack SDLR. SDL is shrouded in confusion and misunderstanding among learners and educators in higher education (Fisher, King, \& Tague, 2001; Hendry \& Ginns, 2009).

Nursing is a complex body of science. Students entering nursing programs without SDLR may exhibit unsatisfactory academic performance. As a result, attrition rates can rise, retention rates can decrease, and student graduation numbers may decline.

\section{Theoretical Framework}

King's (1981) Theory of Goal Attainment (TGA), a nursing theory, and Knowles' (1975) Adult Learning Theory (ALT), an educational theory, were blended to serve as the theoretical basis for this study. The research predictor variables of motivation to learn, learner independence, and intellectual curiosity were congruent with the nursing concepts of learning, self, and growth and development in Personal Systems, one of King's three dynamic interacting systems toward goal attainment, and the educational concepts of proactive learner, learner initiative, and psychological development in Knowles' ALT. The compilation of six key concepts clarified the individuality of the three predictor variables explaining the phenomenon of SDLR.

\section{King's TGA}

King (1981) described the essence of nursing and the interactional patterns and goals that govern the nurse-patient relationship. Theoretically, interaction goals are established, a plan of action is devised, and continuous transactions between the nurse and patient result in the attainment of goals. King's TGA is centered 
on the relationship that develops between nurses and patients and the goals, needs, and values of the nurse, with the intentions of influencing the nurse-patient interaction process and eventually the outcomes.

King's (1981) TGA is a middle-range theory and was generated directly from King's Conceptual System. Key concepts of King's Conceptual System are classified under three dynamic interacting systems: Personal Systems (Individual), Interpersonal Systems (Groups), and Social Systems (Society). With the understanding of the three interacting systems in King's (1981) TGA, this researcher identified the concepts of self, learning, and growth and development within King's Personal Systems as being closely related to the three predictor study variables of motivation to learn, learner independence, and intellectual curiosity.

King (1981) believed that every nurse-patient relationship is based upon the assumption that every human being is of equal worth and value, that every relationship is sustained by justice, and the nurse maintains a responsibility to continuously enhance the competence and skills of the patient. The nurse-client relationship that this theory portrays is similar to the relationship that a nurse educator has with a student. Two strangers come together, establish an understanding of each other, and develop an initial sense of trust for one another. The expectations of the nurse educator are provided to the student in advance; preferably on the first day of class when the course syllabus is provided and reviewed with the student. Together with discussion and cooperation, realistic goals are established.

Ideally, the student leaves the classroom with a clear understanding of these goals, and the course of actions needed to accomplish them. The nurse educator is responsible for cultivating and enhancing the competence and skills of the student. The relationship between nurse educators and students plays a part in the assessment and setting of learning goals. Since this personal system interaction most often goes unnoticed, it suggests a natural process of human interaction.

\section{Knowles' ALT}

Early research and writings devoted to SDL by Houle (1961), and later by Tough (1967), established a foundation for Knowles' (1975) efforts in researching and writing of andragogy; the art and science of helping adults learn. Knowles' writings guide adult learners to understand the process of learning and the responsibility the self-directed learner has in his/her own learning. Knowles suggested that human beings grow in capacity and need to be self-directed as an essential component of maturing. This capacity should be protected and nurtured by the learner. There is an increasingly profound psychological need to be independent as humans develop and mature; naturally developing the ability to take on more and more responsibility for one's life and to be increasingly self-directed (Knowles, 1975).

Knowles (1975) equated learning to living, and that every experience in life is a "learning experience" for personal growth and life experiences of learners are resources for learning to augment with the resources of academic experts. He put forward three immediate concepts for SDL: proactive learner, learner initiative, and psychological development. Knowles believes that human beings who take the initiative in learning as proactive learners learn more things and learn better than reactive learners. Education places a heavy responsibility on students to take an active initiative with their own learning. Adult learning is more consistent with students' natural processes of psychological development. "An essential aspect of maturing is developing the ability to take increasing responsibilities for one's own life, to become self-directed" (Knowles, 1975, p. 15).

Knowles' (1975) ALT provides examples of SDL behaviors of students. These include the student 
determining resources needed to learn, formulating learning goals, identifying human and material resources for learning, choosing and implementing appropriate learning strategies, and evaluating learning outcomes. SDL is when "a student takes the initiative, with or without the help of others to accomplish these tasks, that they are self-directed learners" (Knowles, 1975, p. 18). The concepts in Knowles' ALT are interconnected with SDLR predictor variables: motivation to learn, learner independence, and intellectual curiosity.

According to Knowles (1975), teachers and students are positioned in academia to work with each other, setting mutual goals, and learning and growing together, but it is the responsibility of students to be proactive and self-directed. Baccalaureate nursing students should take charge of their learning, develop the skills of inquiry, and act as adult self-directed learners.

\section{Purposes, Assumptions, Research Questions, and Hypothesis}

\section{Purposes of Study}

This study aimed to:

1. Explore the total scores of baccalaureate nursing students on the Academic Motivation Scale (AMS) (Vallerand, Pelletier, Blais, Briére, Senécal, \& Vallières, 1992), the Autonomous Learner Index (ALI) (Abu-Moghli, Khalaf, Halabi, \& Wardam, 2005), the Curiosity and Exploration Inventory II (CEI II) (Kashdan et al., 2009), and the Self-Directed Learning Readiness Scale for Nursing Education (SDLRSNE) (Fisher et al., 2001);

2. Explore the relationships among motivation to learn, learner independence, intellectual curiosity, and SDLR of baccalaureate nursing students.

\section{Assumptions of the Study}

There were three assumptions in this study:

1. Baccalaureate nursing students have the capability to be adult self-directed learners;

2. Schools that held chapter membership in Sigma Theta Tau International (STTI) value the importance of nursing research and advancing the science of nursing in comparison to schools of nursing who do not hold chapter membership;

3. The participating nursing students answered all research questions openly, honestly, and to the best of their ability.

\section{Research Questions}

The following two research questions guided this study:

1. What are motivation to learn, learner independence, intellectual curiosity, and SDLR scores of sophomore baccalaureate nursing students?

2. What are the relationships among motivation to learn, learner independence, intellectual curiosity, and SDLR in sophomore baccalaureate nursing students?

\section{Hypothesis}

The first research question is descriptive in nature; therefore, no hypothesis was needed. The second research question was tested by the hypothesis that the linear combination of motivation to learn, learner independence, and intellectual curiosity will predict SDLR in baccalaureate nursing students better than anyone variable alone. 


\section{Methods}

\section{Sample and Setting}

In order to be included in this study, students were required to meet the inclusion criteria of being male or female, age 18 or older, and sophomores who were enrolled in beginning nursing courses on either a part-time or full-time status in a four-year baccalaureate nursing program. Four randomly selected schools were drawn from the accessible population of 200 U.S. four-year colleges and universities accredited by the Commission on Collegiate Nursing Education or by the National League for Nursing (NLN) Accrediting Commission that held chapter membership in STTI, the International Honor Society of Nursing.

With a desired power of 0.80 , an acceptable significance level 0.05 , and an expected effect size of 0.13 , a minimum necessary sample size for this study was 76 subjects, as determined by the computerized Sample Power Version 2 program. The actual sample size obtained $(N=154)$ was more than sufficient to meet the power needed for this study.

Schools that were eligible to participate had a four-year baccalaureate program with required nursing courses that begin during the sophomore year. There are 454 U.S. baccalaureate nursing educational programs with chapters of STTI and 15 regions in the U.S. designated by this organization. These regions were collapsed into four groups, combining chapters with similar state and region affiliation (see Table 1). The states of Indiana and Pennsylvania were divided across two collapsed groups; therefore, they were represented in two of these groups. All other states were represented in a single group. One school from each of the four groups was randomly selected and solicited to participate in this study. An online random number generator (www.randomizer.org) was utilized to randomly select these four schools of nursing. If any or all randomly selected schools of nursing declined to participate in the study, or the number of participants was not sufficient to meet the necessary sample size, another eligible school of nursing was selected from the associated group. This process was continued until one school of nursing from each group was a willing participant.

Table 1

STTI Regions Collapsed Into Four Groups

\begin{tabular}{|l|l|l|}
\hline Group and regions & $N$ & States \\
\hline Group 1: Regions 1, 2, 5, and 6 & 50 & $\begin{array}{l}\text { Arizona, Louisiana, Oregon, Arkansas, Missouri, Texas, California, Montana, } \\
\text { Washington, Illinois, Nevada, Indiana, and New Mexico }\end{array}$ \\
\hline Group 2: Regions 3, 4, 9, and 10 & 50 & $\begin{array}{l}\text { Colorado, Minnesota, South Dakota, Indiana, Nebraska, Utah, Iowa, North Dakota, } \\
\text { Wisconsin, Kansas, Ohio, Wyoming, Michigan, and Oklahoma }\end{array}$ \\
\hline Group 3: Regions 7, 8, 11, and 14 & 53 & $\begin{array}{l}\text { Alabama, New York, Florida, Pennsylvania, Georgia, South Carolina, Mississippi, } \\
\text { Tennessee, and New Jersey }\end{array}$ \\
\hline Group 4: Regions 12, 13, and 15 & 47 & $\begin{array}{l}\text { Connecticut, Massachusetts, Rhode Island, Delaware, New Hampshire, Vermont, } \\
\text { District of Columbia, Virginia, Maine, North Carolina, West Virginia, Maryland, } \\
\text { and Pennsylvania }\end{array}$ \\
\hline
\end{tabular}

\section{Instrumentation}

The study used five research instruments: (a) demographic questionnaire; (b) AMS; (c) ALI; (d) CEI II; and (e) SDLRSNE.

Demographic questionnaire. The demographic questionnaire included 16 items that described the sample: current enrollment status, academic year, licensure status, degree status, age, gender, ethnicity, marital status, number of children, state attending course, living arrangements, learning preferences, weekly study hours, and 
employment status. The demographic variables that were selected described the sample and determined the population for generalization of the findings.

AMS. The AMS is based on the tenets of self-determination theory, and is comprised of 28 items that can be divided into seven sub-scale scores assessing three types of intrinsic motivation (knowledge, stimulation, and accomplishment), three types of extrinsic motivation (external regulation, introjected regulation, and identified regulation), and amotivation, as well as calculating a total score for motivation (Vallerand et al., 1992). This instrument was developed from the French scale, Echelle de Motivation en Education (EME), by the same authors of the AMS, and designed to measure motivation toward education. An established 7-point Likert scale was used to indicate to what extent each of the items presently corresponds to one of the reasons why the subject goes to college. Higher scores indicate greater motivation for learning. Because the EME was only validated in French, Vallerand et al. (1992) conducted a study that determined the validity and reliability of this scale in English, and renamed it the AMS. The statistical analysis conducted by researchers included confirmatory factor analysis, with the factor model being statistically significant $(p<0.001)$.

ALI. The ALI was designed to measure both independent and dependent learning behaviors (Abu-Moghli et al., 2005). The ALI instrument contains 24 statements, nine of these indicate dependent learning and 15 indicate independent learning. An established 5-point Likert scale was used to measure these 24 learning items, with higher scores indicating greater learner independence. The ALI questionnaire was initially reviewed for content validity by a panel of nurse educators in Jordan. The questionnaire was then pilot tested on a sample of nursing students at four of six Jordanian universities offering a baccalaureate degree in nursing. Abu-Moghli et al. (2005) reported that the instrument was reliable $(\alpha=0.89)$ in measuring learner independence of baccalaureate nursing students. There are no identified U.S. published studies using the ALI. This instrument is the only published scale investigating specifically the learner independence of baccalaureate nursing students. This study revealed a nearly minimal acceptable Cronbach's alpha internal consistency reliability for the ALI $(\alpha=0.68)$. The decision was made by this researcher that this instrument was valid, as the study's findings for Cronbach's alpha internal consistency was an acceptable minimal coefficient.

CEI II. The CEI II was designed to measure the curiosity and exploration of individuals facilitating positive subjective experiences and personal growth opportunities (Kashdan et al., 2009). The 10-item CEI II was developed from the original 28-item CEI. An established 5-point Likert scale makes up this instrument, with higher scores indicating greater intellectual curiosity. A sample of 311 undergraduates from a large, public mid-Atlantic university was asked to participate in a study by Kashdan et al. (2009). Following the collection and analysis of data on the CEI II, researchers determined that there was evidence of the scales ability to accurately measure curiosity $(p=0.01)$. Study results also suggested that the CEI II had acceptable internal consistency reliability $(\alpha=0.83)$ for researchers interested in exploring the effects of intellectual curiosity.

SDLRSNE. Originally developed by Dr. Lucy Guglielmino in 1977, and published in 1978, the Self-Directed Learning Readiness Scale (SDLRS) was an instrument consisting of sub-scales with 58 items measuring SDLR. In the late 1990's, Fisher et al. (2001) redeveloped the SDLRS to be nursing specific. The SDLRSNE tool consists of 29 items and three sub-scales (self-management, desire for learning, and self-control). An established 5-point Likert scale makes up this instrument, with higher scores indicating greater learning readiness. Each item was deemed to reflect the perceived attributes, skills, and motivational factors required of self-directed learners (Fisher et al., 2001). The internal consistency for each component of the scale was estimated using Cronbach coefficient alpha. "For the total item pool $(N=4)$, self-management sub-scale 
( $N=13)$, the desire for learning sub-scale $(N=12)$, and the self-control sub-scale $(N=15)$ were $0.92,0.86$, 0.85 , and 0.83 respectively" (Fisher et al., 2001, p. 520). Fisher and King (2010) later re-examined the factor structure of the three sub-scales within the SDLRSNE. The study results provided evidence of instrument reliability, measuring SDLR for nursing education $(\alpha=0.87)$. The research by Fisher et al. (2001) determined that the three resultant models provided reasonable evidence of construct validity for the three sub-scales of SDLRSNE, as well as the characteristics identified within this SDLRSNE. Fisher and King (2010) later re-examined the factor structure of the three sub-scales with study results providing evidence of instrument reliability, measuring SDLR for nursing education, with all items contributed positively to the internal consistency reliability.

\section{Procedures}

The study was started after obtaining Internal Review Board approval from all institutions involved. The five instruments were organized and assembled into one research booklet, for ease of subjects' completion. All participants were provided with a letter of invitation and explanation of the study, which included an implied informed consent for student voluntary participation in the study. There were no known actual or potential risks to students while participating in the study. There were no direct benefits or costs for the study participants. All collected data were confidential and anonymous. Nursing students completed the study four weeks into the Spring Semester of sophomore year in an on-campus classroom at each selected school of nursing; therefore, the participants completed it in an environment that was familiar to them.

In previous studies, data were collected on either the first day or first week of a new academic semester and prior to receiving a graded score on a learning evaluation. This researcher felt that it was important that the collection of data be at a time other than when it is anticipated that thoughts of being a self-directed learner are high. Completion of the booklet occurred on a separate class day following an exam, quiz, or classroom activity in which a student had been evaluated. Nursing instructors allocated 30 minutes of classroom time for students to complete the research booklet. Upon completion, the instructors collected and returned the completed research booklets. Of the 202 total number of research booklets that were mailed, $182(90 \%)$ were returned. There were 154 (85\%) research booklets that met the inclusion criteria for this study. Data analyses included descriptive and inferential statistics appropriate to answer the research questions. For this study, three predictor variables were entered individually: motivation to learn, learner independence, and intellectual curiosity. Multiple regression analysis determined if any or all predictor variables were able to predict the outcome variable, SDLR.

\section{Findings}

The findings of this study that investigated motivation to learn, learner independence, intellectual curiosity, and SDLR of baccalaureate nursing students were based on analyses of data collected from the five research instruments.

\section{Demographic Data}

Nominal and ordinal level demographic data. Frequencies and percentages were used to describe the categorized nominal and ordinal level data. The majority of the study participants were female, white, single, without children, and enrolled as full-time nursing students. Almost half of the participants lived in the state of Pennsylvania, lived on campus with a roommate, and preferred to study alone. Most participants indicated that 
they learned best by reading the textbook and assigned lectures, and by taking notes as they read and/or listen to music. Most spent 9-16 hours studying a week, and at the same time, were employed during the academic year.

Ratio and interval demographic data. Ratio and interval level demographic data were analyzed using measures of central tendency (mean, median, and mode), and measures of dispersion (range and standard deviation). These findings further detail the study participants. The average age of the participants was 22 years old. The majority of the subjects had no children. The subjects who are employed during the academic year $(N$ $=86$ ) worked an average of 18 hours weekly.

Demographic profile of study sample. The participants' responses on the demographic questionnaire were summarized and analyzed. These steps were done to profile the sample, so it could be compared to the general nursing population. Most study participants were white, female, and below the age of 30. The NLN (2012) conducted an annual survey of U.S. schools of nursing. This survey examined essential data about applications, admissions, and enrollment, retention, and graduation rates; and provided a comprehensive demographic profile of the current student population documenting ethnic-racial identity, gender, and age demographic for the 2010-2011 academic year. The NLN reported that $76 \%$ of nursing students were white, while the remaining students were categorized as "minority". The percentage of students enrolled in nursing programs by gender was $86 \%$ female and $14 \%$ male; $76 \%$ were under the age of 30 years. This study's sample is reflective of the results of the NLN survey, lending credence for generalizability of this study's findings.

\section{Research Question 1}

The first research question asked: What are the motivation to learn, learner independence, intellectual curiosity, and SDLR scores of sophomore baccalaureate nursing students? This question was answered by computing descriptive statistics for scores on each of the research variables. Descriptive statistics were used to describe the basic features of the data in the study: measures of central tendency including mean and mode, measures of dispersion including range and standard deviation, and shape of the distribution including skew and kurtosis. Details of the descriptive statistics are presented in Table 2.

Table 2

Descriptive Statistics of Research Variable Scores $(N=154)$

\begin{tabular}{lccll}
\hline Variable & Mean & $S D$ & Actual range & Possible range \\
\hline Motivation to learn & 152.2 & 20.9 & $77-189$ & $28-196$ \\
Learner independence & 86.2 & 10.1 & $55-105$ & $24-120$ \\
Intellectual curiosity & 35.1 & 7.9 & $13-50$ & $10-50$ \\
SDLR & 119.6 & 13.4 & $63-145$ & $29-145$ \\
\hline
\end{tabular}

Motivation to learn. The scores on the AMS revealed that this sample of sophomore baccalaureate nursing students have a high motivation to learn. Scores approximated a normal curve with skew (-0.81) and kurtosis $(0.75)$ within the acceptable range of plus or minus one. These findings support and extend what is known from published literature associated with the motivation of students in higher education and health profession education. The studies of Vallerand et al. (1992), Pelaccia, Delplancq, Triby, Bartier, Leman, and Dupeyron (2009), and Rose (2011) also revealed that college students had the motivation to learn during the sophomore courses for their major. They reported that these students demonstrated their motivation by their willingness and interest in learning course content and found pleasure and satisfaction in their experiences of learning, sharing, practicing, and demonstrating things that were new to them. Their motivation to learn was 
driven by the recognition that their diligent scholarly efforts would facilitate the outcome of completion of study and their ability to practice their career of choice.

Learner independence. The scores on the ALI revealed that the sophomore baccalaureate nursing students in this study had high learner independence. Scores approximated a normal curve with skew (-0.48) and kurtosis $(0.21)$ within the acceptable range of plus or minus one. These findings support and extend what is known from published literature on learner independence of nursing students in both health profession education and in higher education. The studies of Hawker (2000), Löfmark, Carlsson, and Wikblad (2001), and Abu-Moghli et al. (2005) also revealed that learner independence in baccalaureate nursing students may be encouraged, developed, and nurtured by nurse educators. They reported that nursing students prefer to study alone, and appreciate opportunities where they can demonstrate learner independence in classroom and clinical settings. Additionally, curricula designed to challenge and invite nursing students to become actively involved in the learning process create an environment conducive to learner independence.

Intellectual curiosity. The scores on the CEI II revealed that sophomore baccalaureate nursing students have high intellectual curiosity. Scores approximated a normal curve with skew (-0.29) and kurtosis (-0.48) within the acceptable range of plus or minus one. These findings support and extend what is known from published literature on intellectual curiosity of nursing students in both health profession education and in higher education. Intellectual curiosity, as reported by Kashdan et al. (2009), is distinctive, as it has overlapping attributes with intrinsic motivation and interest. Researchers led by Kashdan identified curiosity as the willingness, and perhaps the desire to continually accumulate new abilities and experiences, recognizing, embracing, and seeking out new knowledge. Similarly, Dyche and Epstein's (2011) theory-driven conceptual exploration and qualitative review of literature on intellectual curiosity of students in medical education found that intellectual curiosity flourished in educational environments that promote the student's responsibility for his/her own learning. In other words, students demonstrating learner independence are more likely to also have intellectual curiosity. Similar findings were reported in Eason's (2010) study, which examined ways to foster intellectual curiosity and lifelong learning in nurses. Eason also found that environments and cultures that support learning ignite intellectual curiosity.

SDLR. The scores on the SDLRSNE revealed that baccalaureate nursing students have moderately high SDLR for nursing education. Scores differed from a normal curve in that, although the skew (-0.84) was within the limits of normalcy, kurtosis (1.46) revealed a somewhat peaked curve. The study's findings support published empirical evidence literature on SDLR in health profession education and in the higher education. The studies of Fisher and King (2009), Hendry and Ginns (2009), and Smedley (2010) discovered that students entering their first year of study, more specifically, their first week of class, reported themselves as ready to be self-directed learners. Being ready for SDL includes taking the initiative and having self-understanding and acceptance of the responsibility of one's own learning. Hendry and Ginns (2009) reported that students enrolled in first year major courses, commonly have thoughts of self-confidence, and a strong belief in their ability to do well. Similarly, the participants in this study who were in one of their first major courses had a moderately high SDLR. Kocaman, Dicle, and Ugur (2009) and Klunklin, Viseskul, Sripusanapan, and Turale (2010) investigated the SDLR of undergraduate nursing students enrolled in schools of nursing, and similarly discovered that "readiness" of nursing students was at a high level, and increased from the first year of the program through the final year. In these two studies, nursing students were asked to complete the SDLRSNE on the first day of class in their nursing major. Unlike prior studies, the current study participants were asked to 
complete the scale in mid-second semester of the sophomore year. The consistent results in the studies are mutually supportive, as high and moderately high levels of SDLR were identified in participating students at the sophomore as well as in the middle in their first year of study. As data were collected mid-semester with these students, the findings of this study extend what is known about SDLR in nursing students.

\section{Research Question 2/Hypothesis 1}

The second research question asked: What are the relationships among motivation to learn, learner independence, intellectual curiosity, and SDLR in sophomore baccalaureate nursing students? This research question was answered by testing the hypothesis which stated that the linear combination of motivation to learn, learner independence, and intellectual curiosity predicts SDLR in baccalaureate nursing students better than anyone variable alone. This hypothesis was tested by computing a stepwise multiple regression analysis. For this study, three predictor variables were entered individually: motivation to learn, learner independence, and intellectual curiosity. Multiple regression analysis determined if any or all predictor variables were able to predict the outcome variable, SDLR. Although this study found that sophomore baccalaureate nursing students had moderately high intellectual curiosity, and intellectual curiosity was independently significantly related to SDLR, this predictor variable failed to enter the regression equation due to multicollinearity. As a result of the moderately strong relationship with the other two predictor variables, intellectual curiosity did not contribute sufficient unique explanatory power to the regression equation in predicting SDLR of baccalaureate nursing students. Details of the stepwise multiple regression analysis are presented in Table 3.

Table 3

Stepwise Multiple Regression of Learner Independence and Motivation to Learn on SDLR

\begin{tabular}{llllrll}
\hline Model & $R$ & $R^{2}$ & $R^{2} \Delta$ & $F$ & $D f$ & $p$ \\
\hline 1. Learner independence & 0.78 & 0.601 & 0.601 & 228.85 & 1,152 & $<0.001$ \\
2. Motivation to learn & 0.80 & 0.635 & 0.034 & 14.27 & 1,151 & $<0.001$ \\
\hline
\end{tabular}

Additional Analyses

Additional analyses were computed to determine if relationships existed between selected demographic variables and the study variables. Further analyses were computed to determine if differences existed between female and male students, part-time and full-time enrollment status, and the study variables. Additional analyses were calculated to determine if differences existed among the four schools of nursing based on their state location, and the study variables. Pearson correlations, independent $t$-tests, and one-way Analysis of Variance (ANOVA) were computed to determine relationships and differences.

Pearson correlations. Pearson correlations were computed to explore the inter-correlations among the three predictor variables. Analyses revealed that the predictor variables were all significantly related with positive and moderately high correlations. These variables, motivation to learn, learner independence, and intellectual curiosity, shared from $29 \%$ to $34 \%$ of their variance (see Table 4 ).

Pearson correlations were computed to determine if there were any significant relationships between selected demographic variables (age in years, number and children, and weekly work hours), and the study variables of motivation to learn, learner independence, intellectual curiosity, and SDLR outcome variable. Findings indicated that there were no statistically significant correlations between any demographic variable and the study variables. 
Table 4

Pearson Correlations of Motivation to Learn, Learner Independence, and Intellectual Curiosity $(N=154)$

\begin{tabular}{llllll}
\hline & \multicolumn{3}{c}{ Learner independence } & & Intellectual curiosity \\
\hline \multirow{3}{*}{ Motivation to learn } & $r$ & 0.54 & $r$ & 0.58 \\
& $p$ & $<0.001$ & & $r^{2}$ & $<0.001$ \\
& $r^{2}$ & 0.29 & & $r^{2}$ & 0.34 \\
\hline \multirow{3}{*}{ Learner independence } & - & - & $r$ & 0.57 \\
& - & - & $p$ & $<0.001$ \\
& - & - & $r^{2}$ & 0.33 \\
\hline
\end{tabular}

Independent $\boldsymbol{t}$-tests. Independent $t$-tests were computed to determine if there were differences between female students $(N=139)$ and male students $(N=15)$, and to determine if there were differences in enrollment status, full-time $(N=150)$ and part-time $(N=4)$, on motivation to learn, learner independence, intellectual curiosity, or SDLR scores. There were no statistically significant differences between any of the groups on any of the study variables.

One-way ANOVA. One-way ANOVA was used to examine differences among the schools of nursing based on their location in the states of Pennsylvania $(N=65)$, Indiana $(N=32)$, and Louisiana $(N=57)$, on motivation to learn, learner independence, intellectual curiosity, and SDLR scores. Descriptive statistics revealed a mean and standard deviation score for each state for the four study variables.

With the exception of motivation to learn, findings indicated no statistically significant differences among the states on the remaining three study variables. Findings revealed higher motivation to learn scores in students who attended nursing school in Louisiana $(M=159.3 ; S D=19.65)$ were higher $\left(F_{(2,151)}=5.98\right.$; $p=0.003)$ than scores for nursing students who attended nursing school in Pennsylvania $(M=146.68$; $S D=19.85)$. However, motivation to learn scores of students who attended nursing school in Indiana $(M=150.78 ; S D=22.29)$ did not materially differ from scores of students in Pennsylvania or Louisiana, as the mean score of the nursing school in Louisiana was approximately midway between the mean scores of the other two states.

\section{Results and Discussion}

The implications of this study may have an impact on nursing science and research and nursing education. The total scores on instruments used in this study found that baccalaureate nursing students having high learner independence, high motivation to learn, and high intellectual curiosity for nursing education. Furthermore, it was discovered that the linear combination of two predictor variables predicted SDLR in baccalaureate nursing students better than anyone variable alone. Consequently, nurse educators and nursing students may now have a better understanding of SDLR for nursing education. Although attrition rates continue to rise and retention rates continue to decrease, the outcomes show no evidence that lack of SDLR as being a reason for these occurrences.

The overarching aim of researching SDLR of baccalaureate nursing students was to influence nursing education by identifying predictors of SDLR, and to improve the ways in which nurse educators identify a student's readiness to learn nursing. Nurse educators have the primary responsibility of educating nursing students. Nursing students have responsibility for their learning. Nurse educators are held accountable by schools of nursing to guide, support, and lead by example. Nurse educators wishing to develop learner 
independence and motivation to learn in their students must demonstrate both of these characteristics to their students. This can be accomplished by educators advancing their knowledge of the profession of nursing, pursuing an advanced degree in nursing education and/or practice, staying current of nursing trends by reading nursing journals, conducting and participating in nursing research, and presenting research findings at local, regional, and international venues for nurses and other healthcare professionals. Other ways include creating new courses for nursing education and incorporating innovative teaching and learning techniques in classroom and clinical settings. Students may admire these professional efforts, and see them as innovated and self-directed. As a result, nursing students may be more likely to emulate these and other similar behaviors.

Nurse educators are role models for nursing students. Nursing students likely perceive them as experienced, skilled, and knowledgeable of all aspects of the nursing profession. It is a recommendation that nurse educators look beyond assigned textbook material, discovering alternative scholarly resources that can be integrated in nursing courses. Examples include guest speakers, live and prerecorded educational videos, and visual models. Nursing students may view this extracurricular effort as particularly beneficial to their learning experience. Courses can also be designed to enhance students' SDLR. Identifying obstacles to learner independence and/or motivation to learn, and offer methods to diminish or overcome them. This will promote an educational climate that will foster learning principles, student autonomy, and mutual responsibility for learning.

The practice of SDL can be encouraged through teaching strategies and assessment processes enabling students to take control of their own learning. Nurse educators can also synthesize several teaching pedagogies and develop student/teacher learning partnerships focusing on the demonstration of the study's predictive characteristics for SDLR. Nurse educators who design ways to support motivated students and encourage learner independence will create an atmosphere conducive for SDLR in their nursing students. Giving students a sense of control and responsibility for their learning, creating a welcoming learning environment, encouraging self-reflection, making educational goals high but attainable, providing opportunities for success, and making content interesting and enjoyable to learn are ways for nurse educators to accomplish this.

The research findings for SDLR contribute and augment traditional methods of teaching, guidance, and support for nursing students. Nurse educators often have insight that will help their students meet course objectives. They can refer to the above-mentioned predictors, learner independence and motivation to learn, for prescriptive action. Nurse educators who identify students falling below academic expectations may detect lack of learner independence and/or a decrease in their motivation to learn, and therefore are without readiness for SDL. Nurse educators may intervene early once this is identified. Students may be connected with college and university academic support services to assist with test-taking, note-taking, and study techniques. Additionally, the support services can also offer targeted developmental learning activities promoting independence and motivation.

The findings of this study led to implications for nursing education. Namely, to develop nursing curriculum, sequence learning materials, and present assignments and activities that support their students' learner independence and motivation to learn. The support of nursing administration within their school of nursing is crucial. This support is especially recommended when nurse educators revise and design curriculum enhancing learner independence and motivation to learn in their nursing students. Nurse educators must act as leaders for their students, demonstrating these same characteristics. In creating this optimal environment for SDLR, nursing administration and nurse educators must work cohesively. 


\section{Conclusions}

The following conclusions can be drawn from this study:

1. There is evidence that sophomore baccalaureate nursing students are independent and motivated learners, are intellectually curious, and are ready for SDL;

2. There is evidence that the combination of learner independence and motivation to learn predicts SDLR in sophomore baccalaureate nursing students;

3. There are no relationships between selected demographic variables (age in years, number and children, and weekly work hours) and the study variables of motivation to learn, learner independence, intellectual curiosity, and the outcome variable, SDLR;

4. There are no differences between female and male nursing students on motivation to learn, learner independence, intellectual curiosity, or SDLR;

5. There are no differences between part-time and full-time enrollment status on motivation to learn, learner independence, intellectual curiosity, or SDLR;

6. There is no evidence that differences exist among the participating schools of nursing based on their state location on motivation to learn, learner independence, intellectual curiosity, and SDLR.

\section{Recommendations for Future Research}

The following recommendations for future research are intended to support, contribute, and advance the current body of knowledge of SDLR in nursing science and research and nursing education:

1. An interventional study, with random assignment to intervention and control groups, exploring the SDLR of nursing students before and after formal changes are made to nursing curriculum;

2. A study exploring the sub-scales of the SDLRSNE (self-management, desire for learning, and self-control);

3. A study further exploring the extension of King's TAG from clinical nursing practice into nursing education.

4. A study of SDLR with the purpose to create a new educational practice theory applying to nursing education with possibilities for use in the disciplines of education, psychology, or others.

The investigation of SDLR in nursing education should not cease with this study, rather, it warrants further attention and research efforts.

\section{References}

Abu-Moghli, F., Khalaf, I., Halabi, J., \& Wardam, L. (2005). Jordanian baccalaureate nursing students' perception of their learning styles. International Council of Nurses, 52, 39-45.

Ainoda, A., Onishi, H., \& Yasuda, Y. (2005). Definitions and goals of self-directed in contemporary medical education literature. Annals of the Academy of Medicine, 34, 286-290.

American Association of Colleges of Nursing (AACN). (2012). About AACN. Retrieved from http://www.aacn.nche.edu

Dyche, L., \& Epstein, R. (2011). Curiosity and medical education. Medical Education, 45, 663-668.

Eason, T. (2010). Lifelong learning: Fostering a culture of curiosity. Creative Nursing, 16, 155-159. doi: 10.1891/1078-4535.16.4. 155

Fisher, M., \& King, J. (2010). The Self-Directed Learning Readiness Scale for nursing education revisited: A confirmatory factor analysis. Nurse Education Today, 30, 44-48.

Fisher, M., King, J., \& Tague, G. (2001). Development of a self-directed learning readiness scale for nursing education. Nurse Education Today, 21, 516-529.

Garrison, D. R. (1997). Self-directed learning: Toward a comprehensive model. Adult Education Quarterly, 48, 18-33. 
Guglielmino, L. M. (1977). Development of the Self-Directed Learning Readiness Scale. Dissertation Abstracts International, 38 , 6467A.

Hawker, L. (2000). From teacher dependence to learner dependence: Case study from the Dubai Women's College. Paper presented at The Technological Education and National Development Conference, Abu Dhabi, Dubai.

Hendry, G. D., \& Ginns, P. (2009). Readiness for self-directed learning: Validation of a new scale with medical students. Med Teach, 31, 918-920.

Houle, C. O. (1961). The inquiring mind. Madison, W.I.: University of Wisconsin Press.

Kashdan, T., Gallagher, M., Silvia, P., Winterstein, B., Breen, W., Terhar, D., \& Steger, M. (2009). The Curiosity and Exploration Inventory-II: Development, factor structure, and psychometrics. Journal of Research in Personality, 43, 987-998. doi: 10.1016/j.jrp.2009.04.011

King, I. (1981). A theory for nursing systems, concepts, process. New York, N.Y.: John Wiley \& Sons.

Klunklin, A., Viseskul, N., Sripusanapan, A., \& Turale, S. (2010). Readiness for self-directed learning among nursing students in Thailand. Nursing and Health Sciences, 12, 177-181.

Knowles, M. (1975). Self-directed learning. Chicago, I.L.: Follett.

Kocaman, G., Dicle, A., \& Ugur, A. (2009). A longitudinal analysis of the self-directed learning readiness level of nursing students enrolled is a problem-based curriculum. Journal of Nursing Education, 48, 286-290. doi: 10.9999/01484834-2009 0416-09

Löfmark, A., Carlsson, M., \& Wikblad, K. (2001). Student nurses' perception of independence of supervision during clinical nursing practice. Journal of Clinical Nursing, 10, 86-93.

National League for Nursing (NLN). (2012). Nursing education statistics. Retrieved from http://www.nln.org

Pelaccia, T., Delplancq, H., Triby, E., Bartier, J., Leman, C., \& Dupeyron, J. (2009). Impact of training periods in the emergency department on the motivation of health care students to learn. Medical Education, 43, 462-469.

Robinson, E., \& Niemer, L. (2010). A peer mentor tutor program for academic success in nursing. Nursing Education Research, 31, 286-289.

Rose, S. (2011). Academic success of nursing students: Does motivation matter? Teaching and Learning in Nursing, 6, 181-184.

Sigma Theta Tau International (STTI). (2012). Sigma Theta Tau International Organizational fact sheet. Retrieved from http://www.nursingsociety.org

Smedley, A. (2010). The self-directed learning readiness of first year bachelor of nursing students. Journal of Research in Nursing, $12,373-385$.

Tough, A. (1967). Learning without a teacher. Toronto, Canada: Ontario Institute for Studies in Education.

Vallerand, R., Pelletier, L., Blais, M., Briére, N., Senécal, C., \& Vallières, E. (1992). The Academic Motivation Scale: A measure of intrinsic, extrinsic, and amotivation in education. Educational and Psychological Measurement, 52, 1003-1017. 